\title{
INCONSTITUCIONALIDAD DE LA INMUNIDAD PARLAMENTARIA DERIVADA DE LA REFORMA A LA LEY ORGÁNICA DEL CONGRESO NACIONAL
}

\author{
Fatyma Meryzuan Corrales Rivera ${ }^{1}$ \\ Evel Carolina García Flores ${ }^{2}$
}

DOI: $\underline{\text { https://doi.org/10.5377/Ird.v41i1.10504 }}$

"Un estado donde queden impunes las insolencia y la libertad de hacerlo todo,

\section{RESUMEN:} termina por hundirse en el abismo." -Sófocles.

En esta investigación se tratara de figuras jurídicas tales como la inmunidad parlamentaria y la inconstitucionalidad, ambas relacionadas con las funciones y atribuciones del poder legislativo, que corresponden a la elaboración, interpretación, modificación y derogación de la ley en consonancia con el manejo de fondos públicos y el impacto que este genera en el derecho hondureño, Por otro lado demostrar que con los privilegios que genera la reciente reforma a la ley orgánica del poder legislativo conlleva a la desviación de estos fondos para asuntos totalmente ajenos a su propósito, estas actuaciones quedan bajo la supervisión y auditoria del tribunal superior de cuentas, el cual deja en suspenso cualquier responsabilidad generada de la malversación de caudales públicos.

Por lo tanto estos decretos contravienen derechos y garantías establecidas en la constitución de la república, como ser principalmente el derecho a la igualdad, el principio de legalidad, el principio de irretroactividad, las atribuciones del poder ejecutivo, del poder judicial y por ultimo del ministerio público.

\section{PALABRAS CLAVE:}

Inconstitucionalidad, inmunidad parlamentaria, impunidad, fondos públicos, malversación, reforma, blindaje, prerrogativa.

Fecha de recepción: 30 de julio de 2020 Fecha de aprobación: 18 de noviembre de 2020

\footnotetext{
1 Estudiante de la Facultad de Ciencias Jurídicas, pasante bloque de clase XI, Universidad Nacional Autónoma de Honduras (UNAH), Correo Electrónico: meryzuan@gmaill.com

2 Estudiante de la Facultad de Ciencias Jurídicas, pasante bloque de clase XI, Universidad Nacional Autónoma de Honduras (UNAH), Correo Electrónico: gevelcarolina@yahoo.com
} 


\title{
UNCONSTITUTIONALITY IN THE PARLIAMENTARY INMUNITY ORIGINATED THROUGH THE AMENDEMENT MADE TO THE ORGANIC LAW OF THE HONDURAN CONGRESS
}

\author{
Fatyma Meryzuan Corrales Rivera ${ }^{3}$ \\ Evel Carolina García Flores ${ }^{4}$
}

DOI: https://doi.org/10.5377/Ird.v41i1.10504

"A state where insolence and the freedom to do everything go unpunished, it ends up sinking into the abyss. " -Sophocles.

\section{ABSTRACT:}

In the following research we will be talking about law figures such as Parliamentary Immunity and the Unconstitutionality of the law, both related with the functions and attributions of the congress, which correspond to the creation, interpretation, modification and repealing of the law in harmony with the management of the public funds and its impact in the Honduran law system. On the other hand, demonstrate that the privileges product of this recent modification of the Legislative Power Organic Law will result in a deviation of these funds for businesses totally alien of their purpose, such activities will be subject of supervision and audit by the Superior Court of Audit, and this will lead to suspension of any responsibility generated of an embezzlement of public funds.

Therefore the following act is in contravention of guarantees and rights stated in the constitution mainly for instance, the equality right, the legality principle, the retroactivity principle, Executive power, Judicial power and the public ministry attributions.

\section{KEYWORDS:}

Unconstitutionality, parliamentary immunity, impunity, public funds, embezzlement, amend, protection, prerogative.

Date received: July 30, 2020 Approval date: November 18, 2020

\footnotetext{
3 Student of the Facultad de Ciencias Jurídicas, intern block of class XI, Universidad Nacional Autónoma de Honduras (UNAH), Email: meryzuan@gmaill.com

4. Student of the Facultad de Ciencias Jurídicas, intern block of class XI, Universidad Nacional Autónoma de Honduras (UNAH), Email: gevelcarolina@yahoo.com
} 


\section{INTRODUCCIÓN}

Inmunidad derivada en su etimología del latín Inmmunis, integrada por "in" partícula privativa, y "munis" obligación; es decir, el no obligado, el exento de carga, cubierto de pena o persecución ${ }^{5}$. La inmunidad parlamentaria es una figura que ha existido desde la edad media, se encontró originalmente en el derecho inglés y su propósito era proteger la libertad corporal de los parlamentarios y evitar los abusos a los que los sometía el monarca, dicha inmunidad se esparció en todo el continente Europeo con el paso de los años y se incorporó en el sistema jurídico de los países latinoamericanos, pero hoy en día solo se conserva en países como Chile, Uruguay, Argentina, Perú para dar un ejemplo. En Honduras, dicha figura jurídica ha dado pie para la comisión de delitos relacionados con la administración de caudales públicos y ha creado una esfera de impunidad respecto a la persecución legal de dichos delitos ya que por su actividad parlamentaria, estos funcionarios se ven exentos de responsabilidad civil, penal y administrativa.

\section{METODOLOGÍA}

Tipo de investigación: investigación jurídica doctrinal y jurídica filosófica de la normativa suprema de hondureña, metodología junto con un análisis, lógico e histórico jurídica, análisis síntesis inductivo deductivo jurídico, haciendo uso de jurisprudencia. Ampliando el panorama con la aplicación de entrevista a docentes de la facultad ciencias jurídica de la

5 CABAnEllas guillermo, Diccionario Enciclopédico de Derecho Usual: Tomo IV: F-K- $31^{\mathrm{a}}$ ed., pág. 471, Buenos Aires. Heliasta, 2009.
UNAH, y magistrados de la corte suprema de justicia de la sala de lo constitucional.

\section{ANTECEDENTES DE LA INMUNIDAD PARLAMENTARIA}

La figura de la inmunidad parlamentaria tiene su origen en el continente europeo, surgió inicialmente en Inglaterra durante la edad media como un privilegio del cual gozaban miembros del parlamento, en principio solo contaba de una protección para movilizarse llamada Coming, Remaining \& Returning que consistía en viajar al parlamento, permanecer y regresar de él con seguridades solo exclusivamente a los parlamentarios y sus servidores ${ }^{6}$.

Más adelante la inmunidad parlamentaria se vio plasmada en The Bill of Rights mediante el cual se declaraban los derechos y libertades de los sujetos y los asuntos concernientes a la sucesión de las corona, en su artículo 9 establecía el derecho a discurso y debates o procedimientos del parlamento y que estos no eran sujetos a cuestionamientos por ninguna corte o lugar fuera del parlamento ${ }^{7}$. Eventualmente en Francia durante el auge de la revolución francesa, este privilegio parlamentario fue derogado alegando Interés nacional, justicia debida al pueblo y el principio de igualdad, pero en el año 1795 cuando la época del terror había terminado se presentó una moción para incluirlo nuevamente al cuerpo jurídico francés, aunque esta vez fue añadido con más minuciosidad

6 MAY ERKSINE. (1844). Parliamentary Practice. Pág.94. New York City, LexisNexis.

7 JACK MALCOLM, GORDON RICHARD. (2013). Parliamentary Privilege: Evolution or Codification? Pág.11 Londres, Constitution Society. 
y desde entonces ha permanecido en los textos constitucionales franceses solo para esparcirse e ir evolucionando en el derecho constitucional contemporáneo en todo el mundo. ${ }^{8}$

En Latinoamérica históricamente se incorpora la inmunidad parlamentaria como tal, pero comprendida como aforamiento o fuero especial, en otras palabras si hay "hummus bonus iuris" es decir, indicio de un probable delito, el parlamentario vota si con lugar o no, de ser con lugar se da el aforamiento que es un modelo convencional donde altos funcionarios son juzgados por otros altos funcionarios representantes del pueblo, de ser sin lugar la decisión es inapelable.

\section{CARACTERÍSTICAS Y \\ DIFERENCIAS ENTRE INMUNIDAD PARLAMENTARIA Y FUERO PARLAMENTARIO}

\section{Diferencias entre Inmunidad Parlamentaria y Fuero Parlamentario}

Llegados a este punto es imprescindible realizar una diferenciación sobre los términos inmunidad parlamentaria $\mathrm{y}$ fuero parlamentario:

La Inmunidad Parlamentaria que consiste en una garantía otorgada a los diputados respecto a las opiniones que puedan verter en el ejercicio de su cargo y por las cuales no podrán ser censurados u amonestados.

8 Hardt S. (2013). Parliamentary Immunity: A Comprehensive Study of the Systems of Parliamentary Immunity of the United Kingdom, France and the Netherlands in a European Context, Pág. 129-199. Maastricht, Maastricht University.
El Fuero Parlamentario: por otra parte se refiere a la garantía de carácter procesal de la que gozan los funcionarios públicos por las cuales no son sujetos a responsabilidades, penales, administrativas o civiles por las acciones que realicen durante el ejercicio de sus funciones.

El sentido final de la inmunidad, es decir, la protección del cuerpo legislativo como tal y no de sus miembros en particular; se les otorga la protección a los parlamentarios en la medida que representan al órgano parlamentario y en su calidad de tales, no como un derecho subjetivo. ${ }^{9}$

En relación al estudio de campo realizado, que consistió en diversas entrevistas a varios conocedores del tema de las prerrogativas parlamentarias. De acuerdo a los entrevistados, la reforma llevada a cabo en la ley orgánica del Poder Legislativo la cual ampliaremos más adelante de esta investigación, no consiste en una inmunidad parlamentaria per se sino en un tipo de fuero parlamentario.

\section{Características de la inmunidad parlamentaria}

La característica esencial es que va dirigida a la actividad legislativa del parlamentario, como protección en su carácter de diputados o senadores representantes en su caso del pueblo y asegurar el cumplimiento de las funciones manifestadas por dicha representación que no sea obstaculizado el ejercicio recto y correcto

9 Latorre, Boza, Derik, Docente de la Pontificia Universidad Católica del Perú y Vocal del Tribunal de Contrataciones del Estado de Peru, articulo jurídico, revista derecho y sociedad 31. Pág. 163. 
de la legislatura ${ }^{10}$. Otra característica es que busca proteger al diputado en su integridad personal, debido a que este puede ser vital de importancia al momento del voto para un tema de bastante relevancia para el país.

- La inmunidad parlamentaria no tiene un alcance absoluto. En efecto, tiene dos limitaciones. La primera, de carácter material, pues no se refiere a actos ajenos al ejercicio de la función parlamentaria. La segunda, de carácter temporal (duración del mandato), ya que "su La Inmunidad Parlamentaria alcance se reduce a condicionar la responsabilidad del parlamentario a la autorización que debe otorgar la cámara o el órgano competente de la misma..." Esta autorización es totalmente discrecional del órgano competente ${ }^{11}$.

- Funcionalidad: cuando hablamos del carácter funcional de las prerrogativas nos referimos a que estas atienden razones referentes al cargo de representación de un diputado, es decir que el carácter funcional está directamente relacionada al cargo legislativo.

- Desigualdad: esta trata sobre la disparidad de derechos, y la falta de igualdad ante la ley en relación a aquellas conductas propias de su actividad legislativa que puedan ocasionar un daño a la sociedad y respecto de las cuales no hay una aplicación de sanciones.

10 Murcia, R. L. (19 de Noviembre de 2019). Master en Derecho Constitucional. Seminario de Investigación Jurídica. (F. Corrales, Entrevistador) Tegucigalpa, Honduras.

11 La NUEVA ENCICLOPEDIA JURIDICA (Tomo XII, Editorial e Francisco Seix, Barcelona, España, 1.965, p.p. 721722
- Carácter corporativo: el órgano legislativo en su totalidad goza de la protección de su integridad de representación, es decir que cada miembro esta resguardado de cualquier acción procesal que de alguna manera lo haga ausentarse de otorgar su voto en decisiones en las que sea imprescindible su participación.

- Irrenunciabilidad: Esta característica es sine qua non para el ejercicio de su actividad legislativa, ya que es propia de la función parlamentaria.

- Temporalidad: solo se podrá gozar de inmunidad parlamentaria mientras se este desempeñando su cargo como miembro del poder legislativo. ${ }^{12}$

\section{LA INMUNIDAD PARLAMENTARIA EN EL DERECHO CONSTITUCIONAL HONDUREÑO}

En el derecho hondureño hemos visto de igual manera una evolución en las leyes y una incorporación de distintas figuras jurídicas que se encuentran presentes en las constituciones de otros países, un aspecto importante a destacar es que la inmunidad parlamentaria se da en el contexto del parlamento en la cámara de los comunes o lores, en la realidad de la situación específica de Honduras no se cuenta con un sistema bicameral, sino unicameral con el Congreso Nacional.

La inmunidad parlamentaria en principio fue agregada en la Constitución del año 1957 se podría decir para proteger la independencia

12 Sandoval Ninoska. La Inmunidad Parlamentaria en la Legislación Nicaragüense, Universidad Nacional Autónoma de Nicaragua, pag. 31-32, Managua, 2012. 
entre poderes y brindar un Estado de derecho, la inmunidad parlamentaria fue considerada como un fuero que le brindaba a los parlamentarios en este caso a los congresistas, diferentes prerrogativas las cuales se encontraban declaradas en el artículo $185^{13}$ y se aplicaban desde el momento ser electos al cargo de diputados y se encontraban enumeradas de la siguiente manera:

1. De inmunidad personal para no ser detenidos, acusados ni juzgados aun en estado de sitio, si el Congreso no los declara previamente con lugar a formación de causa ${ }^{14}$; es decir que se dé lugar al proceso de investigación y juzgamiento por parte de autoridad competente.

2. No ser llamados al servicio militar sin su consentimiento ${ }^{15}$; dicho en otras palabras ellos podian decidir si prestaban el servicio militar o no, contrario sensu de los particulares específicamente los hombres estaban obligados a prestar el servicio militar.

3. No ser responsables por sus opiniones $o$ iniciativas parlamentarias en ningún tiempo ${ }^{16}$; es decir, no se podía ejercer acción ni por opiniones que dieren lugar a delitos contra el honor como ser injurias o calumnias aun después cesar de ejercer sus funciones como parlamentarios.

13 Decreto Ley No. 21 de la Constitución de la Republica de Honduras de fecha 19 de diciembre de 1957.

14 Numeral 1 artículo 185, Decreto Ley No. 21 de la Constitución de la Republica de Honduras de fecha 19 de diciembre de 1957.

15 Numeral 2, artículo 185, Decreto Ley No. 21 de la Constitución de la Republica de Honduras de fecha 19 de diciembre de 1957.

16 Numeral 3, artículo 185, Decreto Ley No. 21 de la Constitución de la Republica de Honduras de fecha 19 de diciembre de 1957.
4. No ser demandados civilmente desde quince días antes hasta quince días después de las sesiones ordinarias y extraordinarias del Congreso, salvo el caso de reconvención ${ }^{17}$.

En la constitución del año 1965 las prerrogativas pasaron al artículo $177^{18}$, aunque su contenido seguía igual la única diferencia es que aquí gozaban de este fuero los candidatos y parlamentarios ya electos, la siguiente constitución del año 1982 establecía las garantías de protección parlamentarias en el artículo $200^{19}$, sin embargo el contenido de este si se modificó y amplio, en otras palabras, se expandido a objetos que eran extraños a la idea por la cual se originó la inmunidad que era la protección de la acción legislativa y brindaba protección en caso de que los diputados pudieran ser sometidos a registro personal, vehículos y domicilios, a no ser detenidos ni juzgados salvo en caso que hubiesen sido sorprendidos cometiendo delitos contra la vida e integridad corporal en cuyo caso podían ser detenidos por orden de los tribunales y permanecer en arresto domiciliario mientras se rendía caución o el congreso resolviera el asunto.

Lo cual generó una impunidad muy amplia ya que era muy bizarro dieren lugar a formación de causa, en esta constitución se seguía disfrutando del no prestar servicio militar en tiempo de guerra, de no ser responsables por las iniciativas de ley ni opiniones vertidas, ni 17 Numeral 4, artículo 185, Decreto Ley No. 21 de la Constitución de la Republica de Honduras de fecha 19 de diciembre de 1957.

18 Decreto Ley No. 20, De la Constitución de la Republica de Honduras de fecha 3 de junio de 1965.

19 Decreto Ley No. 131, De la Constitución de la republica de Honduras de fecha 11 de enero de 1982. 
votos emitidos durante el ejercicio de su cargo, y por último se añadieron el agotamiento de la vía administrativa en caso de infracción y una vez agotada esta se recurriría a la acción penal y también gozaban del derecho a no declarar sobre hechos que terceras personas les hubieran confiado en virtud de su investidura, todo lo anterior era aplicable a los diputados del congreso nacional y esta vez añadiendo incluso a los candidatos de los partidos políticos desde el momento en que hubiesen sido nominados.

En cambio 17 años después, para precisar en el año de 1999, siendo presidente del congreso Rafael Pineda Ponce se hace una reforma en el artículo 200 de la constitución del año 1982 bajo Decreto Legislativo No. 92-99 del 11 de junio de 1999 y ratificado constitucionalmente, mediante Decreto legislativo No. 31-2000 del 11 de abril del 2000, dicha reforma eliminaba la declaratoria de formación a causa, en caso de encontrar a los diputados en flagrancia de cometer delito contra la vida e integridad corporal, que mereciere pena de reclusión. En este caso pudiendo ser puesto inmediatamente a la orden de los tribunales y esto por los motivos expuestos el considerando primero donde encontramos se hace una explicación de los límites de la inmunidad parlamentaria e indica que "es una prerrogativa otorgada solamente para no ser responsable de sus iniciativas de ley, ni por sus opiniones vertidas, manifestaciones $y$ votos emitidos, en el desempeño de sus funciones y responsabilidades".

En el considerando segundo, “que la redacción de los artículos 200 y 205 numeral 15) es sumamente amplia y que se extiende a aspectos que no deberían estar comprendidos en el concepto de inmunidad y que se plantea la necesidad de su revisión a efectos de delimitar sus alcances y evitar los excesos y abusos"

Considerando tercero "que es procedente modificar aquellos numerales de los artículos 200 y 205 constitucional, para adecuarlos al verdadero concepto de inmunidad en el ejercicio de las funciones públicas".

A lo anterior podemos decir de forma muy acertada se dio dicha reforma, luego en el año 2003 el articulo 200 fue derogado por el Decreto No.175-2003 el 28 de octubre del 2003 y ratificado por el Decreto No. 105-2004 del 27 de julio del 2004, publicado en el diario oficial "La Gaceta" No. 30,492 del 11 de septiembre del 2004, dentro sus considerandos se hace la aseveración del principio de igualdad ante la ley y la negación de clases privilegiadas, debido a que, la inmunidad se ha desfigurado y perdido el fin por el cual se aplicó convirtiendo esta figura en sinónimo de impunidad y que por el bien común se llegó a la derogación del articulado de las prerrogativas parlamentarias, que durante mucho tiempo había servido a los diputados como escudo para evadir las responsabilidades establecidas por la ley respecto de sus actuaciones, las cuales en la mayoría de las veces estaban rodeadas de corrupción.

En relación a este tema el ex mandatario Porfirio Lobo Sosa, declaro en su momento que "la decisión había sido adoptada por el bien del país, ya que se había abusado de la inmunidad y por eso se había llegado a la decisión de eliminarla, ya que todos 
somos iguales ante la ley". Esta moción fue presentada en julio del año 2003 por el liberal Ramón Villeda y en la cual se derogo el artículo $200^{20}$ respectivamente de la constitución de 1982, tal iniciativa fue aprobada por unanimidad con los votos de 128 diputados de los cinco partidos políticos de ese entonces. En consecuencia se le dio una atribución al Poder Judicial de conocer procesos incoados a los más altos funcionarios del Estado y los diputados con la reforma el artículo 313 bajo Decreto No. 105-2004 del 27 de julio del 2004, esto con el fin de evitar futuros casos de corrupción e impunidad.

No obstante, el 16 de octubre del año 2019, las bancadas del partido nacional y liberal conjuntamente decidieron votar a favor de una reforma hecha en la Ley orgánica del Poder Legislativo, la cual según varios diputados de la oposición opinan que viene a reincorporar la figura de la inmunidad parlamentaria, otorgándole un blindaje a los diputados respecto del ejercicio de sus funciones. Esta reforma viene a añadirse en el artículo 10 de dicha ley bajo el literal $\mathrm{A}^{21}$.

\section{INMUNIDAD PARLAMENTARIA DERIVADA DE UNA LEY SECUNDARIA}

\section{1. ¿Activación de Inmunidad Parlamentaria?}

El autor español, Tomas Elorrieta Artaza firma que "la trascendencia de las funciones

20 Articulo 200 derogado por el Decreto No. 175-2003 del 28 de octubre del 2003 y ratificado por el Decreto No. 1052004 del 27 de julio del 2004, publicado en el Diario Oficial La Gaceta No. 30,492 del 11 de septiembre del 2004.

21 Decreto Ley No. 117-2019 del Diario Oficial La Gaceta No. 35,076 de fecha 18 de octubre de 2019. que desempeña el Parlamento ha sido causa de que en todas las legislaciones se concedan a los miembros del Parlamento ciertos privilegios necesarios para garantizar su independencia". Esos privilegios son dos: la inviolabilidad y la inmunidad parlamentaria. La inviolabilidad les protege "por los votos que emitan en las Cámaras" y la inmunidad parlamentaria "consiste en el derecho de todo representante, a no ser procesado sin autorización de la Cámara a la que pertenezca..."22.

Teniendo en claro lo anterior, de la derogación del año 2003 del artículo 200 de la Constitución de la Republica de Honduras, 16 años después, el miércoles 16 de octubre del 2019, se aprobó la reforma al artículo 10 de la Ley Orgánica del Congreso Nacional y junto con ella la Ley Especial para la Gestión, Asignación, Ejecución, Liquidación y Rendición de Cuentas de Fondos Públicos para Proyectos de Orden Social, Comunitarios, Infraestructura y Programas Sociales, también conocida como "Ley de Fondo Departamental" (en delante ley de fondo departamental).

Bajo Decreto No. 256-2013 el artículo $10^{23}$ de la ley orgánica del poder legislativo en Honduras, antes de la reforma rezaba de la siguiente manera "El Pleno del Congreso Nacional es la máxima autoridad y de decisión del Poder Legislativo,..." es decir, solo se hacía afirmación de que el congreso nacional es la autoridad competente de decisión y función legislativa del poder legislativo, ahora bien, en la reforma del artículo 10 del 2019 con el 22 Elorrieta, Tomas, Tratado Elemental de Derecho Político Comparado, Hijos de Reus, Editores, Madrid, España, 1.916, pág. 45.

23 DECRETO Legislativo No. 256-2013 
agregado del literal A, se hace una expansión a sus atribuciones con la definición de "función legislativa" conviene subrayar que dichas atribuciones ya están plasmadas en el artículo 205 de nuestra Constitución hondureña que cuenta con 43 numerales, la que debemos destacar es la del numeral 1 de dicho artículo que establece la función de "crear, interpretar, reforma y derogar las leyes".

Con lo anterior, si bien es cierto la función legislativa es indelegable ya que corresponde al poder legislativo esta función, en consecuencia es lo que se debe esperar en un Estado de Derecho con la división de las facultades que tiene cada uno de los Poderes del Estado, en el párrafo segundo del artículo 10-A determina:

"Que cualquier acción desarrollada en el ejercicio de la misma, no acarrea responsabilidad Penal, Civil y Administrativa a los diputados $y$ diputadas que participen de dicho proceso parlamentario, sin perjuicio de lo establecido en el artículo 205 numeral 3 de la Constitución de la República, siendo el pleno del congreso nacional el órgano competente que debe de valorar cada caso concreto y las consecuencias de la infracción" ${ }^{24}$.

En este extracto del artículo 10-A encontramos una gran similitud a la redacción y disposición de la inmunidad parlamentaria del artículo 200 derogado de la Constitución de la República, que mencionamos de manera más amplia párrafos atrás de esta investigación acerca de la responsabilidad Civil, Penal y Administrativa derivada de la función legislativa. La inmunidad parlamentaria fue derogada de la norma constitucional según

24 Artículo 10-a párrafo 2do. Ley Orgánica del Congreso Nacional Decreto Legislativo No. 117-2019. consenso de todos los sectores de la población para evitar se siguieran cometiendo excesos y abusos por parte de los diputados. Haciendo un análisis a lo antepuesto descubrimos esa inmunidad está siendo aplicada en una ley secundaria, en este caso preciso en la reforma del artículo 10-A de la Ley Orgánica del Congreso Nacional.

También hicimos mención líneas atrás la aprobación el mismo día del Decreto No. 1162019 de la Ley de Fondo Departamental la cual declara en su artículo 1, "es de aplicación obligatoria y sujeta a sus disposiciones Instituciones Públicas del Gobierno Central y/o Descentralizadas, Corporaciones Municipales, Congreso Nacional, Organizaciones No Gubernamentales, Fideicomisos y cualquier Persona Natural o Jurídica, que se les asigne fondos públicos" ${ }^{25}$..., Esta ley da luz verde a los funcionarios que manejen fondos públicos sin temor a ser acusados de delitos de malversación de fondos públicos sin antes previo informe y auditoria del Tribunal Superior de Cuentas (TSC), y en su artículo 16 delimita que:

“...Durante se encuentre vigente la presente auditoría e investigación especial y hasta que el Tribunal Superior de Cuentas (TSC) no emita una resolución definitiva, queda en suspenso cualquier otro tipo de acción administrativa, civil o penal, independientemente de la fase en que se encuentre, en relación a la deducción de cualquier tipo de responsabilidad sobre los fondos que están siendo auditados...26."

25 Artículo 1, Ley Especial para la Gestión, Asignación, Ejecución, Liquidación y Rendición de Cuentas de Fondos Públicos para Proyectos de Orden Social, Comunitarios, Infraestructura y Programas Sociales, también conocida como "Ley de Fondo Departamental, Decreto No. 116-2019 26 Artículo 16, Ley Especial para la Gestión, Asignación, Ejecución, Liquidación y Rendición de Cuentas de Fondos Públicos para Proyectos de Orden Social, Comunitarios, 
Vemos muy claramente que está en consonancia con lo dispuesto en el artículo 10-A de la Ley Orgánica del Congreso Nacional sobre la responsabilidad penal, civil y administrativa, pero más claramente, este caso menciona al Congreso Nacional tenga posibilidad de manejar fondos públicos para la creación de proyectos en comunidades, dicha atribución no la encontramos en el artículo 205 de la Constitución de la Republica. Esto nos podría referir a una "inmunidad" en el manejo de fondos públicos por el hecho de poner en suspenso cualquier acción o proceso de investigación judicial hecha por el Ministerio Público (MP) el cual es el ente encargado de la ejercer de oficio la acción penal pública según los dispuesto en el artículo $232^{27}$ de la Constitución de la República.

INCONSTITUCIONALIDAD DE LA INMUNIDAD PARLAMENTARIA EN HONDURAS

\section{Los cuestionamientos de la legalidad de la reforma al Artículo 10-A de La Ley Orgánica del Poder Legislativo}

En lo que se refiere al articulado 10-A, del Decreto No. 117-2019 genera ciertas dudas acerca del actuar de los funcionarios públicos, el cual debe ser enmarcado dentro de la ley, esta reforma exime de responsabilidad penal, civil y administrativa dentro de su función legislativa, pero como servidores públicos deben una responsabilidad sobre todo acto que ejecuten fuera de la ley en el ejercicio de sus funciones.

Infraestructura y Programas Sociales, también conocida como "Ley de Fondo Departamental, Decreto No. 116-2019 27 Artículo 232 párrafo último, capítulo $\mathrm{V}$ del título $\mathrm{V}$ de los Poderes del Estado, Constitución de la República.
Según unas de las entrevistas realizadas "En los antecedes de la inmunidad parlamentaria en nuestro país ha habido casos de diputados que causaron daño patrimonial, delitos contra la vida que quedaron impunes y no siempre se encontraba con lugar a formación de causa, en particular esta reforma señala que la función legislativa es inviolable y consecuentemente cualquier acción no acarrea responsabilidad penal, civil y administrativa. Se puede afirmar es un blindaje, más que una inmunidad temporal es con ocasión de cualquier acción en ejercicio de la función legislativa no procede responsabilidad, dando un estudio más profundo esta norma es contraria a lo que establece la Constitución en todo un capítulo de la Responsabilidad del Estado y de sus Servidores, el artículo 321 establece que todo acto fuera de la ley es nulo e implica responsabilidad y ellos en ocasión de la labor legislativa cometen algún ilícito, deben de responder sobre sus actos como funcionarios públicos. (Pineda, 2019).

Para ampliar más en el capítulo XIII del título V el artículo 321 Constitucional nos habla del principio de legalidad, señala que los servidores públicos no tienen más facultades que las que la misma ley les confiere, y que todo acto fuera de la ley será nulo, el articulo 322 determina que el funcionario público es aquel que rinde promesa de ley, el artículo 323 establece que los funcionarios son depositarios de la autoridad, responsables legalmente por su conducta oficial, sujetos a la ley y jamás serán superiores a ella, con esto se hace referencia al principio de igualdad, que todos los hondureños son iguales ante la 1 ley ${ }^{28}$, el articulo 324 garantiza que todo 28 
servidor público en el ejercicio de su cargo, infringe la ley será civil y solidariamente responsable junto con el Estado, y esta no reduce la deducción penal y administrativa contra el infractor, por el interés público.

El articulo 325 garantiza que la acción contra los servidores que infrinjan la ley prescribirán en un término de 10 años y 20 años para deducir responsabilidad penal este se contara desde que el servidor haya cesado de sus funciones, junto con el articulo 326 esta persecución solo se ajustara por la simple denuncia. Claramente vemos que el articulado 10-A de la Ley Orgánica del Congreso Nacional contraviene estos artículos constitucionales, por consiguiente el artículo 376 dispone que todas las leyes, decretos, reglamentos, órdenes y demás disposiciones estén en vigor siempre que no contravengan o se opongan a la Constitución.

\section{Límites de la inmunidad parlamentaria derivada del artículo 10-a de la Ley Orgánica del Poder Legislativo}

En cuanto a los límites de la aplicación de la inmunidad parlamentaria en función de la legislación, lo limitan en los considerandos del Decreto No. 117-2019, a la protección legislativa de la integridad física, y que no sean cuestionados o procesados por su mera condición de legislador, abonando más en este tema, en su considerando segundo la protección legislativa incluye dos (2) aspectos esenciales, la seguridad física para no ser intimidados o limitados por acciones de fuerza o disturbios contra su persona y contra la inviolabilidad del recinto parlamentario según Artículo 201 Constitucional, en el mismo considerando suma el reincorporarse la protección jurídica, para no ser objeto de acciones legales en su contra en razón de sus opiniones o accionar legislativo.

En estos primeros dos considerandos se ve reflejada las características básicas de la inmunidad parlamentaria en la protección de la función legislativa esto podría interpretarse como una protección sana.

Pero la contradicción se encuentra en el considerando tercero que señala que con la derogación del Artículo 200 de la Constitución de la República, se suprimió las disposiciones de protección jurídica a los parlamentarios, debido a la falta de conciencia sobre los alcances de la disposición, pero eso quedo claro con la derogación establecida en el considerando segundo del Decreto No.1052004 de fecha 27 de Julio de 2004, publicado en el Diario Oficial "La Gaceta" No.30,49 que la redacción del artículo 200 era sumamente amplia y que se extienda a aspectos que no deberían estar comprendidos en el concepto de inmunidad y que se planteaba la necesidad de su revisión a efectos de delimitar sus alcances y evitar los excesos y abusos, esto debido a los diferentes casos de impunidad que fueron muy publicitados por ejemplo el caso del diputado Carlos Montoya a quien señalaron de cometer un delito contra la vida de uno de sus empleados cuyo caso no paso a dar lugar con formación de causa.

Luego tenemos el considerando cuarto del Decreto No. 117-2019 donde precisan que es un principio y derecho universal de los parlamentos en los Estados Democráticos del mundo, y que es indispensable proceder a 
establecer laprotección jurídica parlamentaria, en la función de crear las leyes.

Para contrarrestar este considerando la inmunidad parlamentaria no es un principio ni derecho universal ya que es como bien se explicó al inicio de esta investigación una prerrogativa, es decir, un privilegio que se aplica según la realidad o situación jurídica de cada país.

INMUNIDAD PARLAMENTARIA EN EL MANEJO DE FONDOS PÚBLICOS DERIVADA DEL ARTÍCULO 16 DE LA LEY DE FONDO DEPARTAMENTAL

Para hondar más en este tema del manejo de fondos públicos en el artículo 245 Constitucional dispone que la función de administración general del Estado esta atribuida al Poder Ejecutivo, a través del Presidente de la República, en el numeral 19 y 30 en su orden señalan, administrar la hacienda pública y dirigir la política económica y financiera del Estado. Teniendo en claro lo anterior junto con lo explicado líneas atrás sobre la independencia de los poderes del Estado y sus atribuciones en el artículo 205 de la Constitución de la Republica en sus numerales 22 y 32 , en su orden, entre ellas está la aprobación del presupuesto general de ingresos y egresos, y exigir explicaciones sobre el manejo que se hace de los fondos a través de los organismos descentralizados, secretarios de estado y funcionarios del gobierno central, en ninguna de las atribuciones señalas por la Constitución al Poder Legislativo le da competencia de manejar fondos públicos para proyectos de desarrollo como señala esta mencionada Ley de Fondo Departamental.
Vale mencionar que esta ley amplía el rango de sujetos capacitados para el manejo de fondos públicos para proyectos de desarrollo en comunidades, en su artículo 1 tiene por objeto establecer las normas relativas a la gestión, asignación, ejecución, liquidación y rendición de cuentas de los fondos públicos que se asignan para proyectos de orden social, comunitarios y programas sociales, a través de las distintas Instituciones Públicas del Gobierno Central y/o Descentralizadas, Corporaciones Municipales, Congreso Nacional, ONGs, Fideicomisos, entes u órganos de derecho privado auxiliares de la Administración Pública y cualquier Persona Natural o Jurídica... evidentemente se incluye al Congreso Nacional con el pretexto del desarrollo de comunidades a través de "proyectos sociales".

Con relación a lo descrito anteriormente, en el considerando segundo del Decreto No. 1162019 que le dio vida a esta ley arguyen que es creada para dar cumplimiento a la "función de representación popular", porque los diputados se encuentran con diferentes comunidades en precariedad y como funcionarios públicos es su deber ayudar a sectores que lo necesitan, pero para eso tiene la facultad de creación de políticas públicas, las cuales pueden poner en práctica legislando para el bien común de la población.

Ahora bien, lo que nos lleva a desarrollar el punto principal de este inciso es el artículo 16 de la Ley de Fondo Departamental, en la cual trata de la Auditoría e Investigación Especial, en otras palabras el proceso a seguir en caso de tener duda del manejo de estos fondos lo que llama la atención son las palabras 
"investigación especial", en este articulado se presenta el proceso para una auditoria, se ordena al Tribunal Superior de Cuentas, que es el ente rector de sistema de control de los recurso públicos que cuenta con una autonomía (independencia) funcional, y administrativa de los poderes del Estado, en adelante (TSC), que proceda a realizar una auditoría e investigación, en la cual el interesado debe presentar una serie de documentación como ser el departamento o municipio donde se ejecutó el proyecto, una lista de beneficiarios entre otros, para que se realice una auditoría documental y de campo para comprobar la ejecución real de los proyectos.

Para cumplir con esta auditoría e investigación especial, el TSC tiene un plazo de 3 años desde la entrada en vigencia de la ley durante se encuentre vigente dicha auditoria e investigación especial y se emita una resolución definitiva por parte del TSC, queda en suspenso cualquier tipo u otra acción ya sea administrativa, civil o penal y además se agrega en el mismo articulado, independientemente en la fases que se encuentre, en relación con cualquier tipo de responsabilidad sobre los fondos que está siendo objeto de auditoria y concluye añadiendo que se puede dar una solvencia o finiquito extendida por le TSC que exime de todo tipo de responsabilidad.

Por otra parte avala la hipótesis que hemos venido desarrollando, de que se trata de una inmunidad, para ser más precisos de una inmunidad disfraza o disimulada que blinda a los parlamentarios de cualquier acción que se produzca en contra de ellos amparados en la reforma del artículo 10-A con la conceptualización de la función legislativa cabe subrayar en su numeral 10 agrega "y otras acciones derivadas de la función en el proceso legislativo", que encaja con lo planteado en el considerando segundo del Decreto No. 1162019 que fue creada para dar cumplimiento a la función de representación popular, es probable decir con lo ya estudiado que esta ley es ajustada para detener los procesos ya incoados contra varios diputados del congreso nacional en relación al tema de malversación de caudales o fondos públicos en detrimentos del interés público.

Al igual vemos que se afecta directamente al Ministerio Publico en sus atribuciones ya que limita la acción de persecución hacia los diputados por delitos que se generen en el cumplimiento de su cargo y función legislativa, como ya lo hemos descrito a profundidad, junto con el proceso que establece la ley de fondo departamental que es una auditoria e investigación especial, pero además de trastocar la constitución en el capítulo completo de la responsabilidad del Estado y sus servidores públicos, contraviene con el derecho de igualdad, principio de legalidad hay una seria violación a este principio respecto a la irretroactividad de la ley señalada en el artículo 96 de la constitución y debido proceso.

Luego tenemos la norma Procesal Penal donde señala en el artículo 414 y $415^{29}$ el proceso especial a seguir en caso de que un diputado o alto funcionario violente las leyes, al igual indica que el órgano competente para conocer de los procesos incoados ya sea requerimiento, acusación o querella a los altos

29 Artículo 414-415. Código Procesal Penal, Decreto No. 9-99 de fecha 20 de mayo de 2000 
funcionarios será la Corte Suprema de Justicia que es el ente encargado de la aplicación de la justicia, para este procedimiento especial se nombra a un magistrado que conocerán del asunto en las etapas preparatorias e intermedias, para conocer en juicio oral y público enterara al tribunal de sentencia que se conforma con cuatro magistrados, tres actuaran en el juicio y uno será sustituto lo mismo pasara en caso de interposición de recurso de apelación.

Podemos observar de que ya existe un procedimiento para poder interpelar las acciones de los diputados en el ejercicio de sus funciones y que no es necesario la intervención del TSC ya que no cuenta con los mecanismos que posee el MP, además de que en la misma Constitución y ley subjetiva penal establece los pasos a seguir para hacer valer el derecho de defensa contemplado en el artículo 82 y demás garantías procesales como ser recurso de reposición apelación y casación.

\section{ANÁLISIS DE LA \\ INCONSTITUCIONALIDAD SOBRE EL FONDO O EN LA FORMA DE LA "INMUNIDAD PARLAMENTARIA DISFRAZADA"}

Para comenzar este análisis citaremos jurisprudencia hondureña de la sentencia SCO-0099-2018 y SCO0588-2018 RI, que habla sobre la inconstitucionalidad de la ley general de ingreso y egresos de la republica del año fiscal 2018 sobre fondo y forma que ha dicho "Que la Constitución establece en su artículo 184 (y artículo 74 de la Ley Sobre Justicia Constitucional) que las Leyes podrán ser declaradas inconstitucionales por razón de forma o de contenido, correspondiéndole a la Corte Suprema de Justicia a través de la Sala de lo Constitucional, el conocimiento y resolución originaria y exclusiva de conocer de esta Garantía, en su carácter de intérprete último y definitivo de la Constitución".

Con relación a esto concretamente la corte suprema de justicia a través de la sala de lo Constitucional es el intérprete último de la constitución, es el ente encargado de determinar los casos en que la creación de leyes contravenga la norma constitucional y dar la respectiva sanción.

Con la reforma a la ley orgánica del poder legislativo en su artículo 10-A y la creación de la Ley de Fondo Departamental se da un precedente de querer lograr una impunidad por parte de los legisladores aplicando esta ley que contraviene a todas luces la Constitución, para recapitular lo desarrollado en esta investigación, se implementó la inmunidad parlamentaria en la Ley Orgánica del Poder legislativo cuando esta ya había sido derogada en el 2004 de la Constitución de la Republica bajo muy certeras razones de impunidad que causo en los diferentes casos que se exteriorizaron a vista pública, además de lesionar el derecho de igualdad consagrado en el artículo 60 Constitucional que enfatiza y señala que en Honduras no existen clases privilegiadas y como tenemos claro la inmunidad es un privilegio que los exime de responsabilidad civil, administrativa y penal.

Además de incoar un proceso especial establecido en la Ley de Fondo Departamental dándole al TSC la facultad de suspender 
cualquier proceso de investigación en tema de malversación de fondos realizado, sin importar la etapa en que se encuentre, hasta que el TSC no dicte resolución o extienda una Constancia de Solvencia o Finiquito la cual exime de cualquier tipo de responsabilidad de naturaleza civil, penal o administrativa en relación a las asignaciones presupuestarias por dicho Tribunal y produciendo el efecto de cosa juzgada quitándole atribuciones al MP el cual es el ente competente de ejercer la persecución penal de oficio .

Podemos decir que la inconstitucionalidad de la reforma de la ley orgánica del poder legislativo y la ley de fondo departamental reside en el fondo y forma de ambas leyes como se vio reflejado en el año 2018 en la sentencia SCO-0099-2018 y SCO0588-2018 RI acerca de la Ley de Presupuesto de Ingresos y Egresos cuyo fallo dictado por la Sala de lo Constitucional declaró inconstitucional de fondo y forma a las reformas dadas en dicha ley ya que contenían exactamente lo que está plasmado en el artículo 16 de la ley de fondo departamental y con ese contenido la corte argumenta en su fallo:

Que descubre que tal reforma trastoca las facultades constitucionales del Ministerio Público (artículo 232 constitucional), al Tribunal Superior de Cuentas (artículo 222 constitucional), subrogando a este último, atribuciones que pertenecen únicamente al Poder Judicial (artículo 304 constitucional) y, confiriendo además al legislativo, facultades exclusivas del Poder Ejecutivo al Congreso Nacional de la República; "también se hace mención de la violación del artículo 96 constitucional.
Para hacer referencia al desarrollo jurisprudencial que ha venido realizando la Sala de lo Constitucional sobre la supremacía constitucional a través del control de constitucionalidad, por medio del reconocimiento de un contenido esencial de nuestra máxima norma, el que prevalece sobre el resto de disposiciones del ordenamiento jurídico" 30 .

En el párrafo anterior se da la inconstitucionalidad en cuestión de fondo por el contenido del artículo 16 donde se le asigna atribuciones al poder legislativo que son propias del poder ejecutivo, poder judicial y ministerio público en cuanto se refiere a la asignación, administración, la acción de persecución penal de oficio, y la dirección técnica y jurídica de la investigación criminal. Y podemos alegar la inconstitucionalidad de forma respecto a que no se siguió el proceso establecido en la constitución artículos 213 al 221 para la aprobación de las leyes y sus reformas, ya que hubo irregularidades al momento de la discusión y votación de dicha ley.

En base al principio Indubio Pro Legislatore que se menciona en esa sentencia SCO-0099-2018 y SCO0588-2018 RI, opera para cuando alguien aduce y denuncia la incompatibilidad de la ley debe dar sus razones jurídicas y reales en la que se supone la misma es inconstitucional, pues la Sala de lo Constitucional reconoce a bien que la libertad de crear leyes le corresponde al Congreso Nacional, además de que la sala no puede obrar de manera tal sin tener claro

30 Recurso de Inconstitucionalidad., SCO-0760-2011 (Sala de lo Constitucional 2011). 
la interpretación conforme al contenido de la Constitución o de no seguir sus formas, la norma impugnada será eliminada, como lo señala el artículo 376 constitucional sin perjuicio de que las mismas estén bajo el control de la judicatura, para la satisfacción de la legalidad, supremacía constitucional y los derechos de las minorías, pero sin afectar la independencia $y$ funcionamiento del Congreso Nacional.

\section{CONCLUSIONES}

- Demostramos que existe una inmunidad parlamentaria derivada de la ley orgánica del poder legislativo que viene a entorpecer la aplicación de la justicia y transgredir el derecho de igualdad, el principio de legalidad y el debido proceso, además de manifestar que esta ley resulta inconstitucional ya que contraviene los artículos 60, 61, 82, 96, 186, 184, 185, 186, 245, 255, 232 Constitucionales.

- En cuanto a los límites encontrados de la inmunidad parlamentaria derivada de la ley orgánica del poder legislativo podemos decir que se basa en crear una impunidad al respeto del tema de malversación de los fondos públicos con la excusa de crear o manejar proyectos sociales, pero en su trasfondo utilizarlos para alzar sus candidaturas políticas ya que quedan eximidos de la responsabilidad civil, penal y administrativa además contrariar los artículos 321, 322, 323, 324, 325, 326, y 327 Constitucionales.

- Las consecuencias que tiene la inmunidad parlamentaria es que blinda de cualquier acción y como lo mencionamos, genera una impunidad afectando directamente al Ministerio Público y Poder Judicial ya que entorpece la aplicación de la justicia, lo que contraviene el interés público además de las comunidades afectadas a las cuales se deben dirigir estos proyectos que contrarían los artículos 232 y 313 Constitucionales.

- Con nuestro último punto encontramos que la inconstitucionalidad reside tanto en el fondo como en la forma de la Ley Orgánica del Poder Legislativo y la Ley de Fondo Departamental ya que contrarían los establecido en la constitución en cuanto a las atribuciones que tiene el congreso nacional y la afectación directa del derecho de igualdad y el principio de legalidad.

\section{BIBLIOGRAFÍA}

CABANELLAS GUILLERMO, Diccionario Enciclopédico de Derecho Usual: Tomo IV: F-K- $31^{\mathrm{a}}$ ed, Buenos Aires. Heliasta, 2009.

MAY ERKSINE. (1844). Parliamentary Practice. Pág.94. New York City, LexisNexis.

JACK MALCOLM, GORDON RICHARD. (2013). Parliamentary Privilege: Evolution or Codification? Pág.11 Londres, Constitution Society.

Pineda, A. (noviembre de 2019). (F. M. Corrales, Entrevistador) Tegucigalpa, Honduras. 
Latorre, Boza, Derik, Docente de la Pontificia Universidad Católica del Perú y Vocal del Tribunal de Contrataciones del Estado de Peru, articulo jurídico, revista derecho y sociedad 31. Pág. 163.

Murcia, R. L. (19 de Noviembre de 2019). Master en Derecho Constitucional. Seminario de Investigación Jurídica. (F. Corrales, Entrevistador) Tegucigalpa, Honduras.

Hardt S. (2013). Parliamentary Immunity: A Comprehensive Study of the Systems of Parliamentary Immunity of the United Kingdom, France and the Netherlands in a European Context, Pág. 129-199. Maastricht, Maastricht University.

La NUEVA ENCICLOPEDIA JURIDICA (Tomo XII, Editorial e Francisco Seix, Barcelona, España, 1.965, p.p. 721-722

Sandoval Ninoska. La Inmunidad Parlamentaria en la Legislación Nicaragüense, Universidad Nacional Autónoma de Nicaragua, pag. 31-32, Managua, 2012.

Articulo 60 Constitución de la Republica.

Decreto Ley No. 21 de la Constitución de la Republica de Honduras de fecha 19 de diciembre de 1957.

Numeral 1 artículo 185, Decreto Ley No. 21 de la Constitución de la Republica de Honduras de fecha 19 de diciembre de 1957.
Numeral 2, artículo 185, Decreto Ley No. 21 de la Constitución de la Republica de Honduras de fecha 19 de diciembre de 1957.

Numeral 3, artículo 185, Decreto Ley No. 21 de la Constitución de la Republica de Honduras de fecha 19 de diciembre de 1957.

Numeral 4, artículo 185, Decreto Ley No. 21 de la Constitución de la Republica de Honduras de fecha 19 de diciembre de 1957.

Decreto Ley No. 20, De la Constitución de la Republica de Honduras de fecha 3 de junio de 1965.

Decreto Ley No. 131, De la Constitución de la republica de Honduras de fecha 11 de enero de 1982.

Articulo 200 derogado por el Decreto No. 175-2003 del 28 de octubre del 2003 y ratificado por el Decreto No. 105-2004 del 27 de julio del 2004, publicado en el Diario Oficial La Gaceta No. 30,492 del 11 de septiembre del 2004.

Decreto Ley No. 117-2019 del Diario Oficial La Gaceta No. 35,076 de fecha 18 de octubre de 2019.

Elorrieta, Tomas, Tratado Elemental de Derecho Político Comparado, Hijos de Reus, Editores, Madrid, España, 1.916, pág. 45 . 
DECRETO Legislativo No. 256-2013

Artículo 10-a párrafo 2do. Ley Orgánica del Congreso Nacional Decreto Legislativo No. 117- 2019.

Artículo 1, Ley Especial para la Gestión, Asignación, Ejecución, Liquidación y Rendición de Cuentas de Fondos Públicos para Proyectos de Orden Social, Comunitarios, Infraestructura y Programas Sociales, también conocida como "Ley de Fondo Departamental, Decreto No. 1162019.

Artículo 16, Ley Especial para la Gestión, Asignación, Ejecución, Liquidación y Rendición de Cuentas de Fondos Públicos para Proyectos de Orden Social, Comunitarios, Infraestructura y Programas Sociales, también conocida como "Ley de Fondo Departamental, Decreto No. 1162019.

Artículo 232 párrafo último, capítulo $\mathrm{V}$ del título V de los Poderes del Estado, Constitución de la República. 